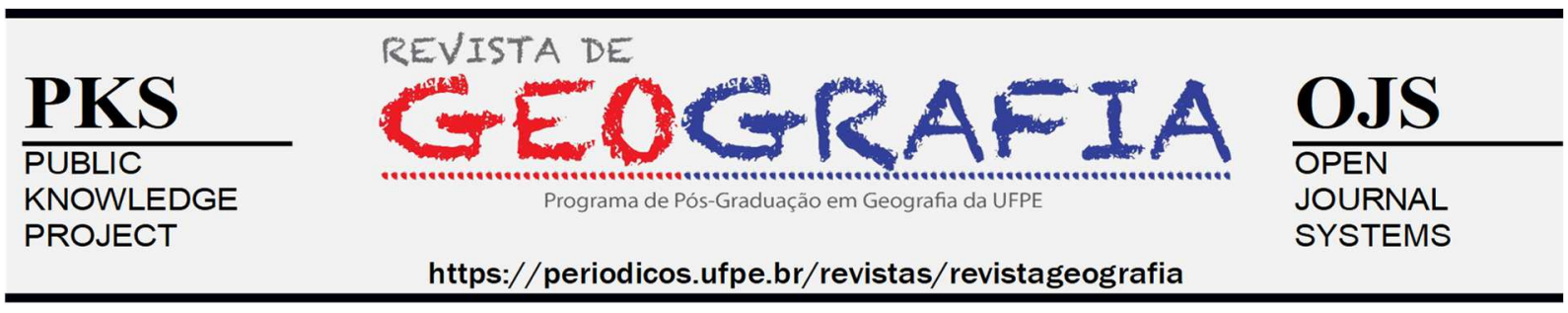

\title{
CARTOGRAFIA DA VULNERABILIDADE SOCIOAMBIENTAL DA ÁREA URBANA DO MUNICÍPIO DE ABREU E LIMA-PE
}

\author{
Cristiana Coutinho Duarte1, João Vitor de Arruda Nóbrega²
}

${ }^{1}$ Professora Adjunta do Departamento de Ciências Geográficas, Universidade Federal de Pernambuco. E-mail: cristiana.durte@ufpe.br; http://orcid.org/0000-0002-5219-3903

2 Graduado em Geografia - Bacharelado pela Universidade Federal de Pernambuco. E-mail: arruda.joaovitor@gmail.com; http://orcid.org/0000-0003-4709-6516

Artigo recebido em 21/10/2020 e aceito em 20/04/2021

\begin{abstract}
RESUMO
A área urbana do município de Abreu e Lima, localizado na Região Metropolitana do Recife (RMR), Pernambuco, é um exemplo da não equidade na distribuição dos proventos sociais, produzindo em alguns grupos da população situações de vulnerabilidade. Diante disso, o objetivo deste trabalho foi desenvolver um mapeamento e análise da vulnerabilidade socioambiental na área urbana desse município, utilizando técnicas básicas de fotointerpretação e geoprocessamento. Foram, então, realizados mapeamentos das unidades homogêneas de uso e de padrões de ocupação urbana e dos indicadores socioeconômicos e ambientais advindos de dados do censo demográfico do IBGE do ano de 2010, agregados por setor censitário (renda média mensal, responsáveis por domicílio alfabetizados, moradores por domicílio, domicílios com abastecimento de água da rede geral, domicílios com esgoto a céu aberto e domicílios com lixo coletado). Posteriormente, os mapas foram reclassificados para os grupos de vulnerabilidade: baixa (1), média (2), alta (3) e muito alta (4) e integrados em ambiente de Sistema de Informações Geográficas. Os resultados indicaram que no geral o mapa segue a realidade observável das localidades, e que as áreas com déficit de infraestrutura estão principalmente fixadas em sítios com alta susceptibilidade ambiental (margens de rios e encostas).
\end{abstract}

Palavras-chave: desigualdade social; geoprocessamento; riscos ambientais.

\section{SOCIO-ENVIRONMENTAL VULNERABILITY CARTOGRAPHY OF THE URBAN AREA OF THE ABREU AND LIMA MUNICIPALITY - PE}

\begin{abstract}
The urban area of the Abreu e Lima municipality located in the Metropolitan Region of Recife (MRR), Pernambuco, is an example of the inequality in the distribution of social benefits, generating situations of vulnerability in some population groups. Therefore, the objective of this work was to develop a socioenvironmental vulnerability mapping of the urban area of this municipality, using basic techniques of photointerpretation and geoprocessing. Then, the mapping of the units of use and occupation pattern and socioeconomic indicators was generated, using data from the IBGE 2010 demographic census,


aggregated by census sector (average monthly income, literate household heads, residents per household, households with general water supply, households with open sewage and households with garbage collected). Subsequently, the maps were reclassified into groups of vulnerability: low (1), medium (2), high (3) and very high (4) and integrated into a Geographic Information System environment. The results indicated that in general the map follows the observable reality of the localities, and that the areas with deficit of infrastructure are fixed mainly in places of high environmental susceptibility (river banks and slopes).

Keywords: socioenvironmental vulnerability; geoprocessing; environmental risks.

\title{
CARTOGRAFÍA DE LA VULNERABILIDAD SOCIOAMBIENTAL DEL ÁREA URBANA DEL MUNICIPIO DE ABREU Y LIMA-PE
}

\begin{abstract}
RESUMEN
El área urbana del municipio de Abreu e Lima, ubicado en la Región Metropolitana de Recife (RMR), Pernambuco, es un ejemplo de inequidad en la distribución de beneficios sociales, produciendo situaciones de vulnerabilidad en algunos grupos poblacionales. Por tanto, el objetivo de este trabajo fue desarrollar un mapeo y análisis de la vulnerabilidad socioambiental en el área urbana de este municipio, utilizando técnicas básicas de fotointerpretación y geoprocesamiento. Luego, se realizó el mapeo de unidades homogéneas de uso y patrones de ocupación urbana e indicadores socioeconómicos y ambientales, utilizando datos del censo demográfico del IBGE 2010, agregados por sector censal (ingreso mensual promedio, jefes de hogar alfabetizados, residentes por hogar, hogares con suministro general de agua, hogares con alcantarillado abierto y hogares con recolección de basura). Posteriormente, los mapas fueron reclasificados en grupos de vulnerabilidad: baja (1), media (2), alta (3) y muy alta (4) e integrados en un entorno de Sistema de Información Geográfica. Los resultados indicaron que en general el mapa sigue la realidad observable de las localidades, y que las áreas con déficit de infraestructura se fijan principalmente en lugares con alta susceptibilidad ambiental (riberas y taludes).
\end{abstract}

Palabras clave: desigualdad social; geoprocesamiento; riesgos ambientales.

\section{INTRODUÇÃO}

Vivemos em uma sociedade em que a desigualdade social priva determinados grupos da oferta de bens e serviços essenciais para a sua sobrevivência. A área urbana do município de Abreu e Lima, localizado na Região Metropolitana do Recife (RMR), é um exemplo da não equidade na distribuição dos proventos sociais, produzindo em alguns grupos da população situações de vulnerabilidade.

A conjuntura atual do município de Abreu e Lima é uma resposta a rápida urbanização face a crescente oferta de empregos para trabalhar na construção ou nas indústrias dos municípios mais periféricos da RMR. Seguindo a lógica dos graus diferenciados de vulnerabilidade destacado por Muccione et al. (2017), nesse processo, alguns grupos fixaram suas moradias em locais com proventos de serviços e bens básicos, no entanto, muitos não 
foram beneficiados com esse crescimento ou sofreram com o desemprego após o término das construções. Isso fez com que a população mais vulnerável socialmente passasse a fixar suas moradias em áreas de baixa especulação imobiliária (OLIVEIRA, 2017) ou, até mesmo, não recomendadas a construção de moradias, como as áreas de encostas suscetíveis a ocorrência de deslizamentos e margens de rios, suscetíveis a inundações (TAGLIANI, 2003; FEITOSA, 2014; MALTA et. al., 2017).

No mesmo sentido como foi evidenciado no estudo de Oliveira et al. (2014), são nas áreas em que estão sobrepostas as situações de suscetibilidade ambiental (moradias em margens de rio e em encostas) e que apresentam baixos indicadores socioambientais (baixa oferta de serviços públicos, exemplo do saneamento básico) que a vulnerabilidade tende a ser mais alta. Além de que estas áreas estão sujeitas a doenças de veiculação hídrica nas épocas mais chuvosas quando geralmente ocorrem as inundações nos corpos hídricos (SOLA et al., 2018). Ou seja, nesse exemplo, a vulnerabilidade afeta uma cadeia de fatores de risco na vida da população para além dos riscos físicos da inundação em si.

Seguindo a mesma supracitada lógica, a ocorrência de deslizamentos nas áreas de encostas com ocupações informais e sem infraestrutura é constante no município de Abreu e Lima. Somente no ano de 2019 cinco pessoas morreram em um deslizamento nesse município durante as fortes chuvas acumuladas no mês de julho (G1, 2019).

Em geral, as áreas ocupadas por moradias, principalmente aquelas de caráter irregular, trazem grandes danos ambientais e sociais, pois são nas áreas de risco a ocorrência de processos do meio físico que vivem grande parte da população que não dispõe de recursos ou renda que propicie melhores condições de habitação (ALCÁNTARA-AYALA, 2002; ALVES, 2009).

Atualmente, além das crescentes desigualdades que caracterizam as sociedades mais complexas dos países em desenvolvimento, existem processos sociais básicos, essenciais, que levam ao surgimento de "fatores de risco" ou criam novas formas de risco em todos os níveis. Os processos sociais e os riscos que eles originam são resultados das decisões humanas moldadas por muitas forças e pressões, causando desastres, portanto, que se entrelaçam rapidamente aos problemas sociais, econômicos, culturais e políticos mais profundos. Assim, a identificação dessas causas básicas do risco de desastres abre caminho para a redução e eliminação por meio de políticas e práticas (OLIVER-SMITH et al., 2017).

O conhecimento do perigo e a identificação dos elementos expostos é o ponto de partida nas pesquisas de risco de desastres. Os elementos considerados como expostos às ameaças/perigos são entendidos em termos de pessoas, infraestrutura, produção, riqueza, 
recursos naturais, dentre outros, localizados na "linha de fogo" do evento físico com variações de intensidade espacial e temporal. Isso dependerá dos diferentes níveis de vulnerabilidade que esses elementos exibem frente ao provável evento físico (WISNER, 2016).

As estruturas socioeconômicas podem produzir ao mesmo tempo condições de vida precárias de determinadas populações e ambientes deteriorados. Essa junção é definida por Freitas et al. (2012) como vulnerabilidade socioambiental. Para Alves (2009) ela representa a sobreposição espacial de situações de pobreza/privação social e de situações de exposição ao risco e/ou degradação ambiental. Neste caso, é de extrema importância e urgência o monitoramento conjunto tanto dos processos físicos quanto das situações de vulnerabilidade em que as populações se encontram, já que estes não ocorrem separadamente. Por isso, o conceito de vulnerabilidade socioambiental é que norteará o desenvolvimento teórico e metodológico da presente pesquisa. A aplicação deste conceito também pode ser identificada nos trabalhos de Deschamps (2008), Alves (2009), Zanella et al. (2013) e Buffon (2018).

Dessa forma, é cada vez mais importante o estudo sistemático da vulnerabilidade distribuída nos espaços, tanto na sua diagnose quanto nas soluções concretas advindas destas, visando a resolução de problemas estruturais e, consequentemente, diminuição das vulnerabilidades. Por isso, o presente estudo tem como objetivo elaborar uma cartografia da vulnerabilidade socioambiental na área urbana do município de Abreu e Lima. Para isso foram delineados os seguintes objetivos específicos: 1) elaborar um mapa de unidades homogêneas de uso/padrões de ocupação; 2) definir e elaborar mapas dos indicadores socioambientais com base no censo demográfico do IBGE de 2010; 3) classificar e definir o índice de vulnerabilidade socioambiental com base na integração dos grupos de variáveis trabalhadas anteriormente.

\section{MATERIAIS E MÉTODOS}

Os procedimentos metodológicos seguirão a ordem estabelecida para o desenvolvimento dos objetivos específicos anteriormente expostos (Figura 1). Iniciando, contudo, com a localização da área de estudo e apresentação de suas principais características. 
Figura 1. Organograma metodológico Fonte: organizado pelos autores

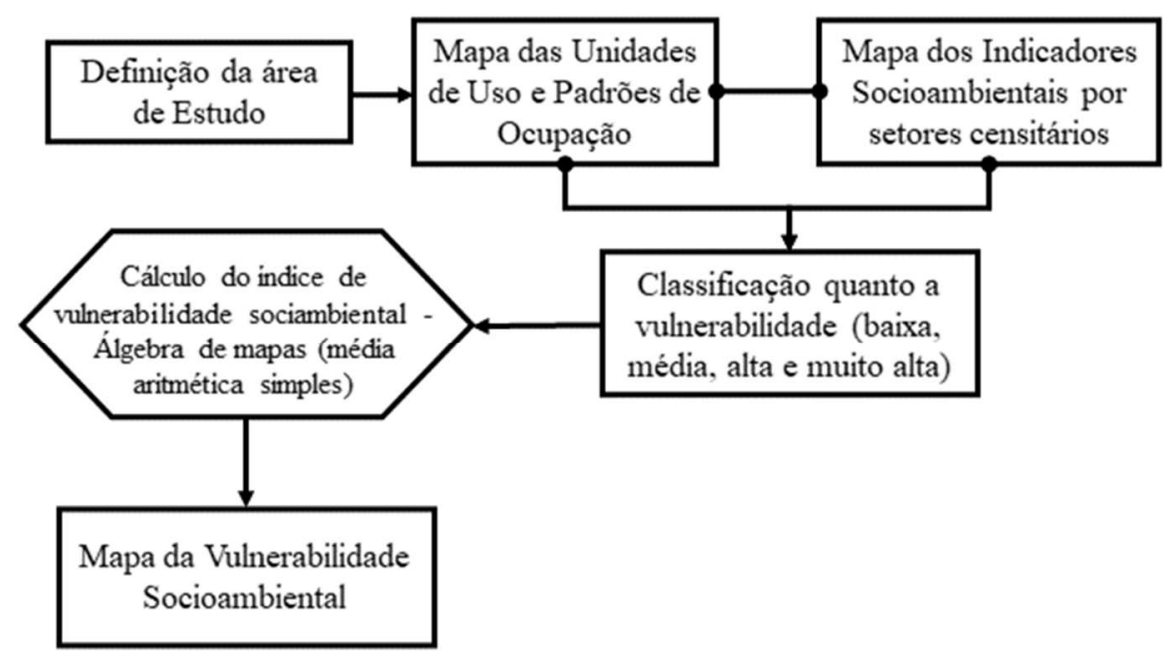

\section{Área de estudo}

A área de estudo está localizada na região urbana do município de Abreu e Lima, pertencente a Região Metropolitana do Recife (RMR), estado de Pernambuco (Figura 2). O município tem uma população total de 94.429 habitantes (IBGE, 2010) e uma área de $126 \mathrm{~km}^{2}$. A população concentra-se em uma pequena área urbana do município com densidade demográfica de 748.29 hab $/ \mathrm{km}^{2}$ e uma taxa de urbanização de 91,74\% (ATLAS DE DESENVOLVIMENTO HUMANO DO BRASIL, 2013).

O relevo do município tem predominância da unidade dos Tabuleiros Costeiros, as quais são formações do tipo sedimentar com um grau de entalhamento variável, tendo vales estreitos e encostas abruptas ou encostas suaves e fundos de vales com amplas várzeas. O clima de Abreu e Lima é caracterizado como Tropical úmido, com média anual de precipitação pluviométrica de $1.752 \mathrm{~mm}$ (SILVA et al., 2016). Conjuntamente, as características de relevo e do clima naturalmente fazem com que a geomorfologia do local siga a dinâmica das vertentes, por exemplo, com movimentos de massa sobre estas superfícies.

\section{Mapa das unidades homogêneas de uso/padrões de ocupação urbana}

O mapeamento das unidades homogêneas de uso e padrões de ocupação foi baseado nos trabalhos de Rossini-Penteado et al (2005), São Paulo (2016) e Medeiros e Grigio (2019), com 
alguns ajustes necessários de acordo com as características do município de Abreu e Lima. As principais alterações foram a exclusão da densidade muito alta, relacionadas aos espaços com edificações verticalizadas, os quais não ocorrem em Abreu e Lima. Também foi retirada a característica esparsa dos padrões de ocupação, pois, como o objetivo deste trabalho foi a análise da área urbana, o adensamento populacional é maior, tendo como resultado o espaçamento não muito distante das moradias. Ainda foram introduzidos os padrões de ocupação em encostas com base no Projeto Viva o Morro (ALHEIROS et al., 2004), pois é uma característica de relevo bastante comum da zona da mata pernambucana. Ainda foram adicionadas unidades de uso de condomínios e conjuntos habitacionais, outra padronização ocupacional bastante comum na RMR; e unidades de uso dos poderes Público e/ou Privado.

Figura 2. Mapa de localização da área urbana do município de Abreu e Lima. Fonte: os autores. Fonte: os autores

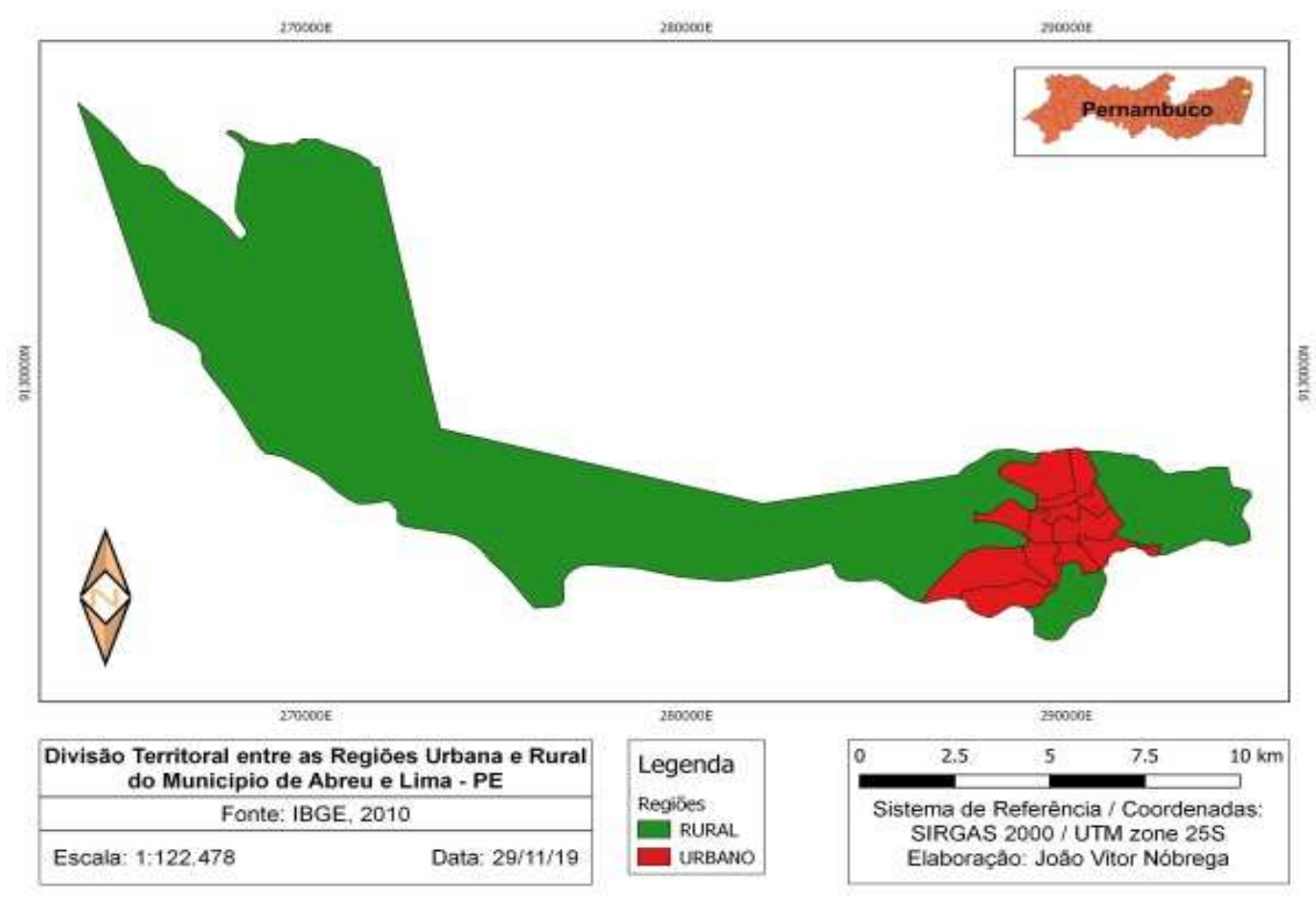

No processo de caracterização das unidades de ocupação, para a vetorização das classes foi utilizada a imagem do Google.cn Satellites referente ao ano de 2017 do mês de novembro, advinda do plugin QuickMapServices do sofware Qgis. Foi necessário definir algumas chaves de identificação nas imagens e em campo afim de facilitar a fotointerpretação e vetorização das classes. No quadro 1 representa-se um exemplo de chave de identificação para uma unidade (U1). 
Para a vetorização das unidades de ocupação em encostas, foi utilizado um Modelo Digital de Elevação (MDE) do satélite ASTER GDEM 2 com resolução de 30 metros, datado de agosto de 2019. A definição das classes de declividades foi baseada na Lei de Uso e Parcelamento do Solo (BRASIL, 1979) quanto à identificação de áreas com restrições ao uso urbano proposto por Valente (1996). Foram vetorizadas como unidades de ocupação em encostas, as localidades com no mínimo $15 \%$ de declividade, e as áreas com adensamento urbano relativamente próximo a esta.

Em áreas que margeiam pequenos rios e/ou córregos, seguiu-se o que preconiza a Lei N 12.651/2012 (BRASIL, 2012), que trata das Áreas de Preservação Permanente. Ou seja, em construções com uma distância de no máximo 30 metros para um curso de água com 10 metros de largura, foram postas como tendo uma estrutura urbana inadequada, independentemente do tipo de construção. A ferramenta utilizada para o cálculo da distância no mapa foi o plugin Medir do Qgis.

Quadro 1. Exemplo de caracterização das unidades homogêneas de uso/ padrões de ocupação

\begin{tabular}{|c|c|c|c|c|c|}
\hline ID & Densidade & $\begin{array}{c}\text { Estágio de } \\
\text { consolidação }\end{array}$ & $\begin{array}{c}\text { Estrutura } \\
\text { Urbana }\end{array}$ & Descrição da classe na superfície & Chave de identificação \\
\hline U1 & Alta & Consolidado & Adequada & $\begin{array}{l}\text { Área com alta densidade de edificações, cuja } \\
\text { superfície é bastante impermeabilizada e pouco } \\
\text { arborizada. Apresenta estruturação urbana em } \\
\text { estágio consolidado. }\end{array}$ & \\
\hline
\end{tabular}

\section{Indicadores socioeconômicos e ambientais}

Para os mapas dos indicadores socioeconômicos e ambientais, a metodologia utilizada foi baseada em Medeiros e Almeida (2015). Foram, então, coletados os dados da Base de informações do Censo Demográfico do IBGE: Resultados do Universo por setor censitário (IBGE, 2010), a saber: renda, escolaridade, atendimento pela rede de esgotos, rede de abastecimento d'água, coleta de resíduos sólidos e população por domicílio. Após isto, foram elaborados os mapas de cada uma destas variáveis para a região urbana do município de Abreu e Lima, utilizando a reclassificação em quatro classes por meio de quebras naturais no software Qgis. 


\section{Índice de vulnerabilidade}

No presente artigo, o cálculo do índice de vulnerabilidade baseou-se na metodologia de classificação do Índice Paulista de Vulnerabilidade Social - IPVS (FUNDAÇÃO SEADE, 2010), com adaptações para as unidades de uso e padrões de ocupação gerados para Abreu e Lima.

O critério de ordenamento urbano é o principal indicador de propensão à vulnerabilidade de uma determinada área, pois, quanto mais inadequada for a estrutura urbana de um local mais vulneráveis serão os indivíduos fixados nestes espaços. Por exemplo, as famílias que vivem em encostas com ordenamento urbano, onde os traçados dos sistemas viários são organizados, em que há estruturas de drenagem, obras com estrutura de contenção de movimentos de massa, destinação correta do lixo, além da disposição de padrões de edificação corretos; terão uma vulnerabilidade baixa. Já as famílias que também vivem nas encostas, porém, em locais onde o ordenamento urbano é inadequado: sem estruturas de drenagem, destinação incorreta do lixo, sem obras de contenção etc.; a vulnerabilidade destas famílias tende a ser alta.

As áreas com inadequação da estrutura urbana, com estágio ainda em fase de consolidação das ocupações e com uma média/baixa densidade de edificações, tendem a ter uma vulnerabilidade muito alta. Pois, como são áreas incipientes em estruturas, os locais são na maior parte das vezes de difícil acesso - em encostas e margens de rios, por exemplo - onde será difícil tanto o acesso a serviços públicos pelos moradores, quanto à oferta destes mesmos serviços pelos poderes públicos.

Já as áreas com vulnerabilidade média, têm como principal causa desta classificação estarem inseridas em locais onde as ocupações estão em estágio de consolidação. É característico de locais afastados do centro urbano onde há certo ordenamento, porém, com uma distância considerável, podendo ter a oferta de serviços/equipamentos públicos prejudicada. Também implica em sítios em que existam quadras com terrenos baldios que não estão tendo manutenções por parte dos proprietários, podendo acarretar lotes com lixo a céu aberto. Este ambiente é ideal para a proliferação de animais vetores de doenças, por exemplo.

A justificativa para a utilização dos indicadores renda média mensal do responsável, domicílios com abastecimento de água, domicílios com lixo coletado e responsáveis alfabetizados; é que a maior quantidade destes em determinado setor censitário, sinalizam que há um aporte de capital e de serviços básicos ofertados a população, e por consequência uma menor vulnerabilidade. 
Os altos valores para as variáveis domicílios com esgoto a céu aberto e número de moradores por domicílio, geralmente indicam uma maior pressão tanto no ambiente daquele setor - com o despejo de água poluída - quanto nos serviços públicos oferecido, com uma maior demanda, por exemplo, de Políticas Públicas para a prevenção ou mitigação de determinadas problemas ambientais.

Para a síntese dos resultados e elaboração do mapa final de vulnerabilidade socioambiental realizou-se o cruzamento do mapa de unidades de uso/padrões de ocupação com o mapa dos indicadores de vulnerabilidade.

Conforme demonstrado anteriormente os intervalos de cada variável foram classificados de acordo com o grau de vulnerabilidade, utilizando-se valores de 1 a 4. Da seguinte forma: vulnerabilidade baixa (valor 1), vulnerabilidade média (valor 2), vulnerabilidade alta (valor 3) e vulnerabilidade muito alta (valor 4). Utilizando-se a coluna com os referidos valores de vulnerabilidade, realizou-se a conversão de todos os sete mapas (padrões de uso e ocupação, renda, abastecimento de água, lixo coletado, esgoto a céu aberto, responsáveis alfabetizados e população) para o formato raster com o plugin rasterizar no Qgis.

Em seguida, por meio de álgebra de mapas aplicou-se uma média aritmética simples (mapa $1+$ mapa $2+$ mapa $3+$ mapa $4+$ mapa $5+$ mapa $6+$ mapa $7 / 7)$ por meio do plugin Calculadora Raster no Qgis. Após isto, o mapa final foi dividido em quatro classes utilizandose o limiar dos grupos de vulnerabilidade socioambiental de 1 a 4.

\section{RESULTADOS E DISCUSSÃO}

Neste item serão detalhadas as unidades de uso e padrões de ocupação, as variáveis socioambientais e suas respectivas classificações quanto a vulnerabilidade. Por fim, serão descritos os resultados do mapa de vulnerabilidade socioambiental da área urbana do município de Abreu e Lima.

\section{Unidades homogêneas de uso/padrões de ocupação urbana classificados quanto a vulnerabilidade}

Foram identificadas 10 unidades homogêneas sobre três tipos de relevo: sobre planícies e no topo dos tabuleiros (U1, U2, U3, U4, U5, U9 e U10), abrangendo $41 \%$ da área urbana, e sobre encostas com declividades consideráveis (U6, U7 e U8), abrangendo 20\% da área. Além dessas unidades também foram classificadas as áreas com vegetação (VD), que ocupam 7\% da 
área, os espaços com vegetação descontínua e/ou solo exposto (Vse), com 18\%, e os locais onde se encontram os equipamentos públicos ou privados (EPP), os quais abrangem 10\% da área total de estudo (Quadro 2).

Os outros $4 \%$ que não foram contabilizados relacionam-se as lacunas intraunidades da vetorização. Ou seja, quando algumas ruas ou outro tipo de categoria espacial ficou entre duas unidades e não foi vetorizado.

$\mathrm{Na}$ figura 3 visualiza-se o resultado da vetorização das unidades homogêneas de uso/padrões de ocupação urbana, agora reclassificados, entre os grupos de vulnerabilidade de 1 a 4, que são: a vulnerabilidade baixa, vulnerabilidade média, vulnerabilidade alta e vulnerabilidade muito alta, respectivamente.

Quadro 2. Grupos de vulnerabilidade das unidades homogêneas de uso/padrões de ocupação urbana do município de Abreu e Lima

\begin{tabular}{|c|c|c|}
\hline Grupo & Vulnerabilidade & $\begin{array}{c}\text { ID das unidades } \\
\text { homogêneas de uso/padrão } \\
\text { de ocupação urbana }\end{array}$ \\
\hline $\mathbf{1}$ & Baixa & U1, U6, U9, VD, EPP e \\
& & VSE \\
\hline $\mathbf{2}$ & Média & U2 \\
\hline $\mathbf{3}$ & Alta & U3, U4, U7 e U10 \\
\hline $\mathbf{4}$ & Muito Alta & U5 e U8 \\
\hline
\end{tabular}

Grande parte das unidades homogêneas de uso/padrões da área urbana abreulimense que se encontram no grupo de baixa vulnerabilidade (1), estão situadas em planícies e em tabuleiros. Nesses ambientes, em quase todos os bairros, excetuando o bairro de Timbó - onde o relevo é mais regular - contêm moradias em continuidade de encostas, porém, com uma boa adequação de infraestrutura. 
Figura 3. Reclassificação para os grupos de vulnerabilidade da distribuição espacial das unidades homogêneas de uso/padrões de ocupação da área urbana de Abreu e Lima - PE. Fonte: os autores

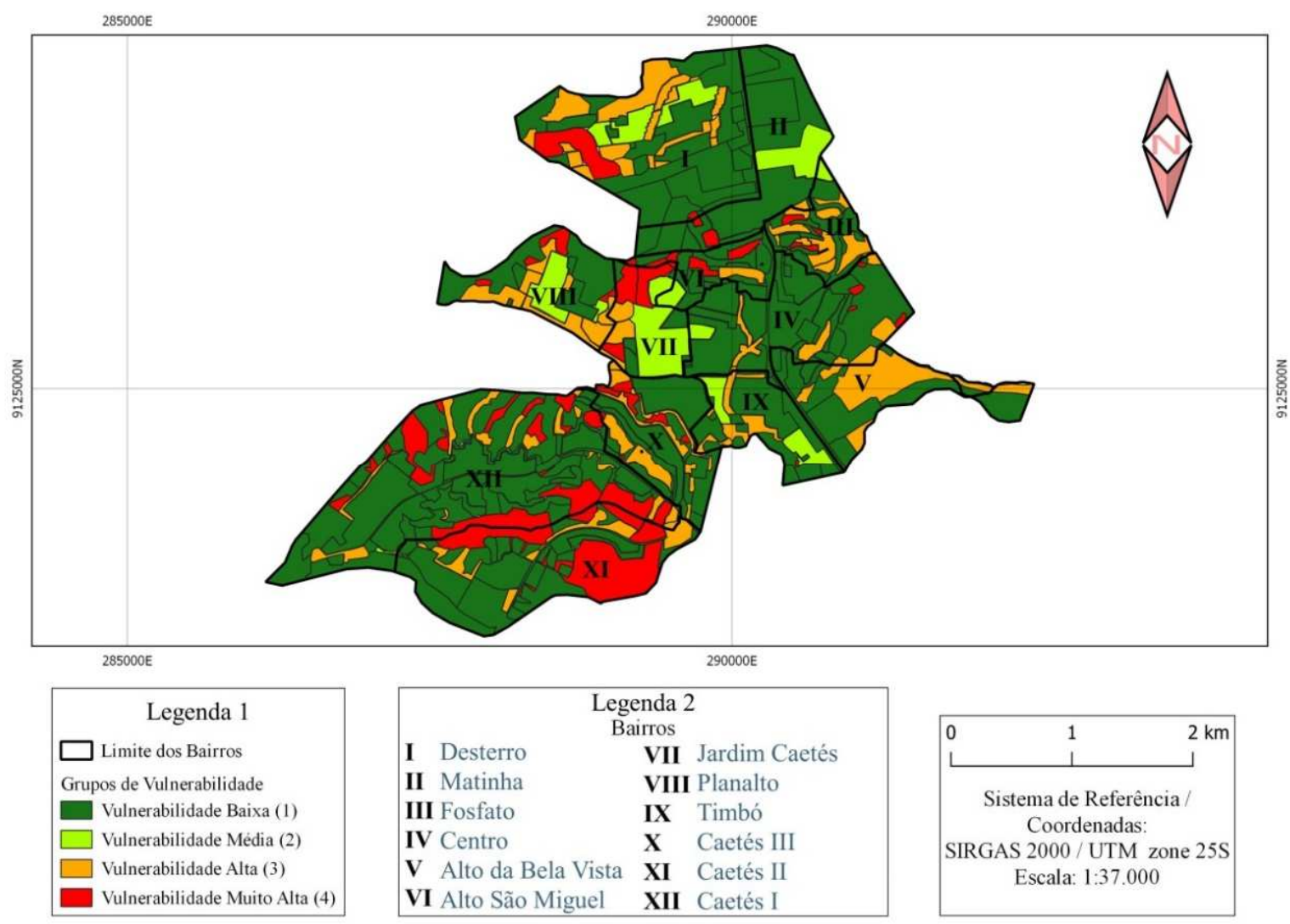

Outra particularidade que sugere um grau de vulnerabilidade baixo em parcelas consideráveis de bairros como Caetés II, Caetés I, Planalto, Desterro e a seção leste do Centro; são as vegetações mais densas e/ou as vegetações descontínuas e solo exposto. Estes bairros estão nos limites territoriais com as regiões rurais do município, que mantêm algumas frações remanescentes de Mata Atlântica.

A principal característica para uma localidade estar inserida no grupo de média vulnerabilidade (2), são os lotes que ainda não foram preenchidos com habitações. Se estes espaços não forem sistematicamente zelados para a eliminação do acúmulo de lixo doméstico - muitas vezes causado pela própria população mesmo havendo coleta de lixo de forma regular -, poderão abrigar insetos e roedores que são vetores de enfermidades que atingem diretamente as populações que ali residem. Além de que na porção leste do bairro de Timbó - onde há uma disposição considerável de lotes vazios, por ser em uma região central próximo da rodovia BR101 e do Distrito Industrial - é uma localidade onde existe um processo de especulação imobiliária, principalmente resguardando o solo para o uso de indústrias e/ou serviços (OLIVEIRA, 2017). 
As regiões que foram classificadas no grupo de vulnerabilidade alta (3) seguem uma característica comum que é a inadequação da estrutura urbana do local. Porém, existem particularidades relativas ao espaço onde estão fixadas que são inerentes a cada uma destas áreas. Por exemplo, nas localidades onde existem moradias em continuidade de encostas com um considerável adensamento populacional, porém, onde a infraestrutura não é tecnicamente correta - disposição irregular dos lotes, ruas desordenadas e/ou não pavimentadas, sem uma drenagem correta, sem obras de contenção em alguns setores - são classificadas como áreas em vulnerabilidade alta.

Já moradias que estão fixadas em margens de rios, independente se com um adensamento populacional alto ou não, são classificadas como áreas com alta vulnerabilidade. Muitas destas habitações até estão incorporadas em locais com uma disposição ordenada dos lotes e vias pavimentadas, porém, como foram construídas próximas aos leitos de pequenos rios, são áreas que ocasionalmente sofrem com inundações.

Ainda no grupo de vulnerabilidade alta (3), constituem tanto as áreas em planícies ou tabuleiros que têm um considerável adensamento populacional e déficit em ordenamento urbano quanto os locais em planícies e tabuleiros que são pouco adensados, mas que também têm deficiência em infraestrutura urbana. Os primeiros são lugares onde a disposição não ordenada dos lotes é característica, além de terem alguns destes onde as vias não são pavimentadas, o que tende a dificultar, por exemplo, a locomoção dos moradores. Enquanto nos segundos, por estarem em estágios iniciais de adensamento têm a disposição das casas e das vias muitas vezes feitas de formas não ordenadas, com ruas na maior parte dos casos sem estarem asfaltadas, dificultando o acesso as casas.

Finalmente, os locais que foram classificados como vulnerabilidade muito alta (4), em linhas gerais, estão situados em lugares com média a baixa densidade de edificações, por consequência estando num estágio de consolidação de sua ocupação, além de sujeitos à inadequação urbana quanto às infraestruturas básicas. Porém, algumas particularidades são observadas quando analisado o mapa da distribuição destes padrões de ocupação. A primeira é a disposição de moradias nas encostas, em que algumas têm vegetação, já outras não têm. Entretanto, todas as áreas destas particularidades não promoveram a adoção de técnicas necessárias para que estas moradias pudessem continuar fixadas nestes morros, como obras de contenção das encostas e sistemas de drenagem. Neste sentido, estas características físicas do terreno fazem com que as moradias estejam em áreas suscetíveis a deslizamentos de terra, o que faz com que a vulnerabilidade destes moradores seja muito alta (DESCHAMPS, 2008). 
Nos locais onde as casas estão dispostas diretamente ou próximas às margens dos rios, dependendo, por exemplo, da intensidade da precipitação, são locais que ocasionalmente são atingidos pelas águas que transbordam dos rios, independente se são feitas obras de dragagem ou canalização. Desta forma, os moradores que residem nestas localidades estão fortemente expostos às intempéries climáticas, o que dá um nível de vulnerabilidade muito alto a estes lugares (FEITOSA, 2014).

\section{Indicadores socioambientais classificados quanto a vulnerabilidade}

A análise dos indicadores socioambientais na área urbana de Abreu e Lima foi realizada com base no percentual de setores censitários - 102 setores - inseridos em algum dos quatro grupos de vulnerabilidade: baixa (1), média (2), alta (3) e muito alta (4); incluindo a sobreposição dos limites territoriais dos 12 bairros com o intuito de localizar mais precisamente onde se encontram as situações de vulnerabilidade.

Como a delimitação dos setores feita pelo IBGE geralmente não leva em conta os aspectos físicos homogêneos de um território, às vezes um mesmo setor encontra-se tanto em áreas com uma susceptibilidade mais alta a um impacto potencial (TAGLIANI, 2003) - como as moradias em encostas e nas margens dos rios - quanto em lugares com uma susceptibilidade menor a potenciais desastres ambientais como as planícies, tabuleiros e as próprias habitações em encostas com infraestrutura adequada. Isso evidencia a limitação da abordagem metodológica da vulnerabilidade somente por dados dos setores censitários e justifica a escolha que foi realizada neste trabalho para o cruzamento das informações censitárias com os dados espaciais dos padrões de ocupação. Os intervalos das variáveis socioambientais classificadas quanto a sua vulnerabilidade podem ser vistos no quadro 3.

Quadro 3. Grupos de vulnerabilidade das variáveis socioambientais coletadas no Censo demográfico do IBGE 2010

\begin{tabular}{|c|c|c|c|c|c|c|}
\hline Vulnerabilidade & $\begin{array}{c}\text { Renda média } \\
\text { mensal dos } \\
\text { responsáveis } \\
\text { pelo domicílio }\end{array}$ & $\begin{array}{c}\text { Domicílios } \\
\text { com } \\
\text { abastecimento } \\
\text { de água da } \\
\text { rede geral }\end{array}$ & $\begin{array}{c}\text { Domicílios } \\
\text { com lixo } \\
\text { coletado }\end{array}$ & $\begin{array}{c}\text { Domicílios } \\
\text { com } \\
\text { esgoto a } \\
\text { céu aberto }\end{array}$ & $\begin{array}{c}\text { Responsáveis } \\
\text { alfabetizados }\end{array}$ & $\begin{array}{c}\text { Moradores domicílio } \\
\text { em dopulação) } \\
\text { (popula }\end{array}$ \\
\hline Baixa (1) & $1057-1416$ & $321-408$ & $333-418$ & $0-18$ & $282-404$ & $58-556$ \\
\hline Média (2) & $471-1057$ & $248-321$ & $250-333$ & $18-54$ & $203-282$ & $556-847$ \\
\hline Alta (3) & $534-741$ & $166-248$ & $174-250$ & $54-103$ & $127-203$ & $847-1127$ \\
\hline Muito Alta (4) & $249-534$ & $15-166$ & $15-174$ & $103-167$ & $12-127$ & $1127-1556$ \\
\hline
\end{tabular}

No quadro 4 e na figura 4A estão o percentual de ocorrência e a distribuição espacial, respectivamente, dos setores censitários levando em consideração os grupos de vulnerabilidade 
para a variável de renda média mensal na porção urbana do município de Abreu e Lima. Uma quantidade ínfima de 0,98\% dos setores censitários se encontra em baixa vulnerabilidade. Outros $29,41 \%$ dos setores estão inseridos em média vulnerabilidade em relação à renda, estando alguns destes tanto em áreas de encostas e margens de rios quanto em padrões de ocupação com uma menor susceptibilidade ambiental.

A maior parte dos setores $(39,21 \%)$ da região urbana abreulimense está em situação de vulnerabilidade alta no que diz respeito à renda média mensal. Além disso, existe um percentual de 30,39\% de setores em condições de vulnerabilidade muito alta em relação à renda na porção urbana. A localização destes está quase que inteiramente ligada a situações de vulnerabilidade ambiental de alguns locais, principalmente as moradias em encostas. Atenção especial deve ser dada aos bairros do Fosfato - 8 dos 9 setores em vulnerabilidade muito alta - e do Planalto - 3 dos 4 setores em vulnerabilidade muito alta.

Somando o percentual de setores em vulnerabilidade alta e muito alta, chega-se a um valor de 69,6\% de locais em circunstâncias de alta vulnerabilidade no quesito renda nos bairros da região urbana de Abreu e Lima. Número bastante alarmante, tendo em vista que a renda é uma das principais variáveis de medição da vulnerabilidade (ALCÁNTARA-AYALA, 2002).

Em relação ao indicador responsáveis alfabetizados (Quadro 5), tendo por base a reclassificação por grupos de vulnerabilidade (Figura 3B), foi identificado que 22,54\% dos setores se inserem no grupo de vulnerabilidade baixa.

Já 38,23\% dos setores - a maior parte - estão incluídos no grupo de vulnerabilidade média (2). Para os setores censitários que estão em situação de vulnerabilidade alta (3), o número é de 29,41\%; os setores estão localizados principalmente em áreas de encosta, o que mostra uma relação entre este indicativo social e a alta susceptibilidade ambiental. Tal assertiva se sustenta ainda mais quando vemos que dos 9,8\% dos setores em vulnerabilidade muito alta (4), também estão localizados sob relevos declivosos.

Ainda por meio da quantificação do percentual dos setores censitários, levando em consideração os grupos de vulnerabilidade, foram encontrados valores muito próximos entre os indicadores da quantidade populacional, de domicílios com abastecimento de água e da coleta de lixo nos domicílios.

Estes números podem ser vistos na no quadro 5. Em geral, uma maior quantidade populacional aumenta a demanda por infraestruturas e serviços públicos. Porém, dependendo da dimensão política do local em questão, a vulnerabilidade tende a ser mais alta se aquele local com grande densidade populacional não tiver plenamente os serviços básicos (poder público 
ineficiente), ou mais baixa se for um local populoso com serviços públicos ofertados de forma mais difundida (poder público mais eficiente).

O percentual de setores censitários que estão inseridos no grupo de vulnerabilidade baixa (1) para os três indicadores tem uma aproximação numérica, em alguns casos até uma igualdade nos valores: $15,68 \%, 15,68 \%$ e 13,72\%; para as variáveis de população, abastecimento de água e coleta de lixo, respectivamente (Quadro 5). A quantidade percentual de setores censitários no grupo de vulnerabilidade média (2) também segue um padrão similar: $34,31 \%, 34,31 \%$ e $35,29 \%$ para os indicadores de população, de abastecimento e de coleta de lixo, em sequência. Já para o número de setores censitários incluídos no grupo de vulnerabilidade alta (3), os valores percentuais são: $38,23 \%, 32,35 \%$ e 29,41\% para os atributos de população, abastecimento de água e coleta de lixo.

Já a quantidade percentual de setores censitários que se inserem no grupo de vulnerabilidade muito alta (4) na questão populacional é de $11,76 \%$, indicando que existem relativamente poucos setores com uma densidade populacional significativa. No indicador de domicílios com abastecimento de água, $17,64 \%$ dos setores se encontram na faixa de vulnerabilidade muito alta. E para a variável de coleta de lixo, 21,56\% dos setores estão na faixa de vulnerabilidade muito alta.

Quadro 4. Percentual dos setores censitários localizados em áreas de baixa, média, alta ou muito alta vulnerabilidade referente aos indicadores de renda média mensal, domicílios com abastecimento de água da rede geral, domicílios com lixo coletado, domicílios com esgoto a céu aberto, responsáveis por domicílios alfabetizados, número de moradores por domicílio.

\begin{tabular}{|c|c|c|c|c|c|c|}
\hline \\
\hline Vulnerabilidade & $\begin{array}{c}\text { Renda média } \\
\text { mensal dos } \\
\text { responsáveis } \\
\text { pelo domicílio } \\
(\%)\end{array}$ & $\begin{array}{c}\text { Domicílios com } \\
\text { abastecimento } \\
\text { de água da rede } \\
\text { geral }(\%)\end{array}$ & $\begin{array}{c}\text { Domicílios } \\
\text { com lixo } \\
\text { coletado } \\
(\%)\end{array}$ & $\begin{array}{c}\text { Domicílios } \\
\text { com esgoto a } \\
\text { céu aberto } \\
(\%)\end{array}$ & $\begin{array}{c}\text { Responsáveis } \\
\text { alfabetizados } \\
(\%)\end{array}$ & $\begin{array}{l}\text { Moradores em } \\
\text { domicílio (\%) }\end{array}$ \\
\hline Baixa (1) & 0,98 & 15,68 & 13,72 & 72,54 & 22,54 & 15,68 \\
\hline Média (2) & 29,41 & 34,31 & 35,29 & 13,72 & 38,23 & 34,31 \\
\hline Alta (3) & 39,21 & 32,35 & 29,41 & 10,78 & 29,41 & 38,23 \\
\hline Muito Alta (4) & 30,39 & 17,64 & 21,56 & 2,94 & 9,80 & 11,76 \\
\hline
\end{tabular}

Fonte: baseado no censo demográfico do IBGE, 2010. 
Figura 4. A - Reclassificação para os Grupos de Vulnerabilidade da Distribuição Espacial da Renda Média Mensal dos Domicílios na Região Urbana de Abreu e Lima - PE, B - Reclassificação para os Grupos de Vulnerabilidade da Distribuição Espacial de Responsável Alfabetizados na Região Urbana de Abreu e Lima PE.
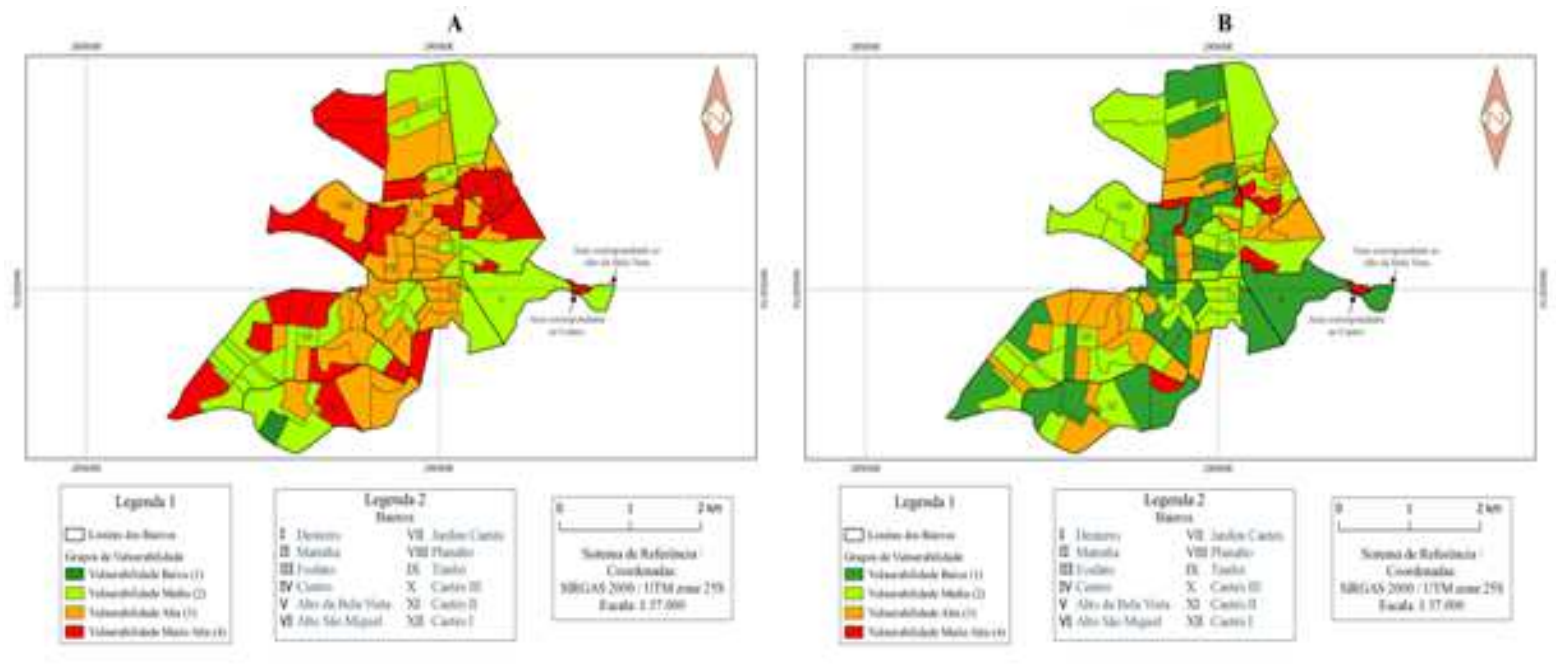

Um exemplo de como a estrutura política pode influenciar na vulnerabilidade de um local, pode ser vista na distribuição espacial dos setores censitários destes três indicadores supracitados nas figuras 5A, 5B e 5C. Os mapas neste caso específico mostram que quanto maior o adensamento populacional - que no geral pode significar uma tendência maior de vulnerabilidade - naquele setor censitário, maior tenderá a ser a oferta de serviços públicos vulnerabilidade mais baixa - de abastecimento de água e de coleta de lixo. Isso implica dizer que na área urbana de Abreu e Lima o adensamento populacional não tem um peso tão grande em direção à alta vulnerabilidade, o que pode indicar uma boa eficiência do poder público na oferta destes serviços.

$\mathrm{Na}$ classificação dos setores censitários por grupos de vulnerabilidade referente à variável de domicílios com esgoto a céu aberto (Quadro 4 e Figura 5D), foi verificado que 72,54\% e $13,72 \%$ dos setores estão em situação de vulnerabilidade baixa (1) e média (2), respectivamente. Estes números retratam que na maior parte do território urbano abreulimense, os domicílios que produzem efluentes de esgoto doméstico diretamente nas vias estão em menores quantidades. O que não significa necessariamente que não sejam encontrados esgoto a céu aberto nas ruas, pois, se tiver apenas um domicílio que cause o escoamento destes efluentes numa via, pode fazer com que o restante das casas - que não despejam efluentes sejam atingidas.

Por fim, o percentual dos setores que estão incluídos nos grupos de vulnerabilidade alta (3) e muito alta (4) são de respectivamente $10,78 \%$ e $2,94 \%$. Apesar de serem valores 
relativamente baixos em comparação com a totalidade da região urbana, algumas características espaciais fazem com que a atenção para a mitigação ou resolução destes problemas seja de fato feita de formas incisivas. Como no exemplo dos setores em alta vulnerabilidade nos bairros do Alto São Miguel, Fosfato e no sentido oeste de Caetés II. Estes estão localizados em áreas de encosta, havendo ainda moradias com padrões de ocupação também deficitários (MALTA et al., 2017).

Figura 5. Reclassificação para os Grupos de Vulnerabilidade da Distribuição Espacial da: a - número de moradores por domicílio; b - abastecimento de água; c - domicílios com lixo coletado; e d - esgoto a céu aberto na Região Urbana de Abreu e Lima - PE.
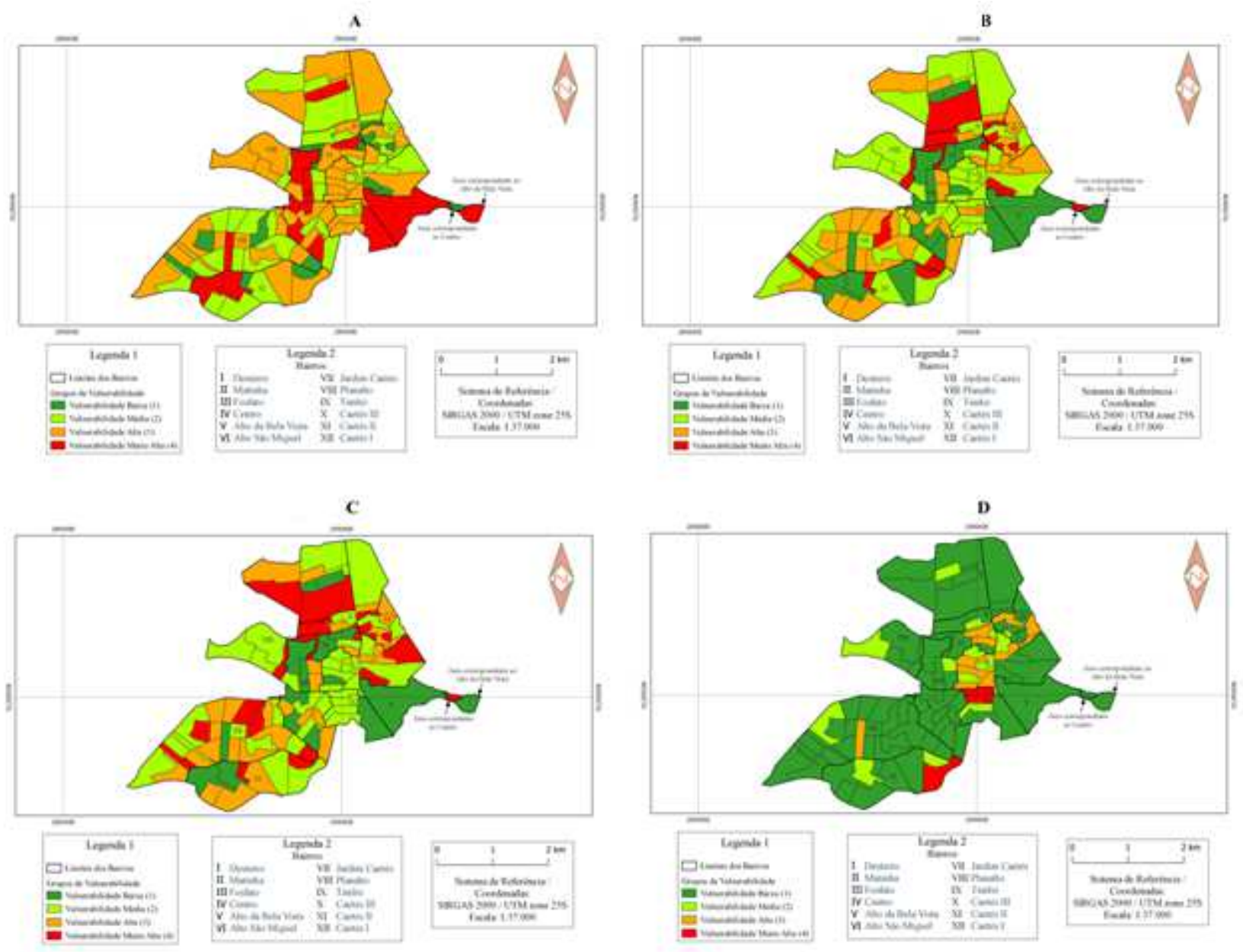

\section{Mapa da Vulnerabilidade Socioambiental}

Cruzando as informações do mapa de unidades homogêneas de uso e padrões de ocupação urbana juntamente com os dos indicadores de vulnerabilidade socioambiental, resultou o mapa da vulnerabilidade socioambiental da área urbana do município de Abreu e Lima (Figura 6 e quadro 5). 
O menor percentual de vulnerabilidade socioambiental que se encontra na área de estudo é de nível baixo (8,49\%) seguido do nível médio que tem um valor bem maior (22,84\%). Estes dois níveis de vulnerabilidade geralmente indicam moradias em padrões de ocupação com uma melhor infraestrutura, tanto em planícies quanto em encostas, por exemplo. Além de vulnerabilidades mais baixas quanto aos indicadores socioambientais. Neste sentido, são as áreas que têm as melhores ofertas dos serviços públicos, por consequência, uma melhor qualidade de vida dos moradores (MUCCIONE, 2017).

Nos níveis alto e muito alto, encontramos a maior parte do território da região urbana, com um percentual de 34,95\% e de 33,70\% respectivamente. Isto evidencia que a área considerada como urbana no município de Abreu e Lima deve ser uma das prioridades do Poder Público na resolução dos eventuais desníveis socioeconômicos e infraestruturais. Várias destas áreas estão sob encostas e em margens de rios sem uma adequação urbana técnica - o que aumenta o grau de riscos ambientais -, além de locais em relevos mais estáveis, como o caso de tabuleiros e planícies, com uma alta vulnerabilidade em relação aos indicadores socioambientais.

Em linhas gerais, quase todos os bairros que comportam vulnerabilidades alta e muito alta têm moradias em margens de rio ou encostas, principalmente as últimas, e baixos indicadores socioambientais (DE OLIVEIRA et al., 2014). Porém, atenção especial em Políticas Públicas deve ser dada ao bairro do Fosfato, onde toda a extensão territorial está sobreposta nas vulnerabilidades alta e muito alta, por conta das moradias fixadas em espaços sem ordenamento urbano adequado.

Outros dois bairros que merecem atenção são o do Planalto e o de Desterro. No primeiro, apesar de algumas superestimações do resultado por conta dos consideráveis tamanhos de alguns setores, os indicadores são reflexos dos padrões de ocupação sem ordenamento urbano em encostas e nos tabuleiros, a baixa distribuição da renda e o grande adensamento populacional. Já em Desterro, mais precisamente na parte oeste, é um bairro com alto grau de vulnerabilidade em grande parte por consequência de baixos indicadores de renda e de coleta de lixo, além de moradias - até mesmo condomínios populares - sem uma adequação urbana eficiente. Em algumas partes as habitações estão em encostas, mesmo que com vegetações fixadas em suas continuidades, mas não têm obras técnicas de infraestrutura para que a vivência das famílias seja sustentável ao longo do tempo.

Nos bairros de Caetés I, Caetés II, Centro, Alto São Miguel e Matinha, existem alguns fragmentos do espaço em vulnerabilidade muito alta por conta das moradias em encostas sem 
ordenamento urbano - obras de contenção, drenagem etc. - além de indicadores socioambientais deficientes.

No bairro de Timbó como um todo, os indicadores de quantidade populacional e renda elevam a vulnerabilidade para níveis altos, condição que fica evidente por conta de boa parte do bairro estar em vulnerabilidade alta. Este resultado pode ser considerado uma superestimação da metodologia do mapa de vulnerabilidade socioambiental causado pelo indicador populacional, com vista dos bons níveis de ordenamento urbano que partes destas áreas inseridas na vulnerabilidade alta possuem.

Figura 6. Distribuição Espacial da Vulnerabilidade Socioambiental na Região Urbana do município de Abreu e Lima.

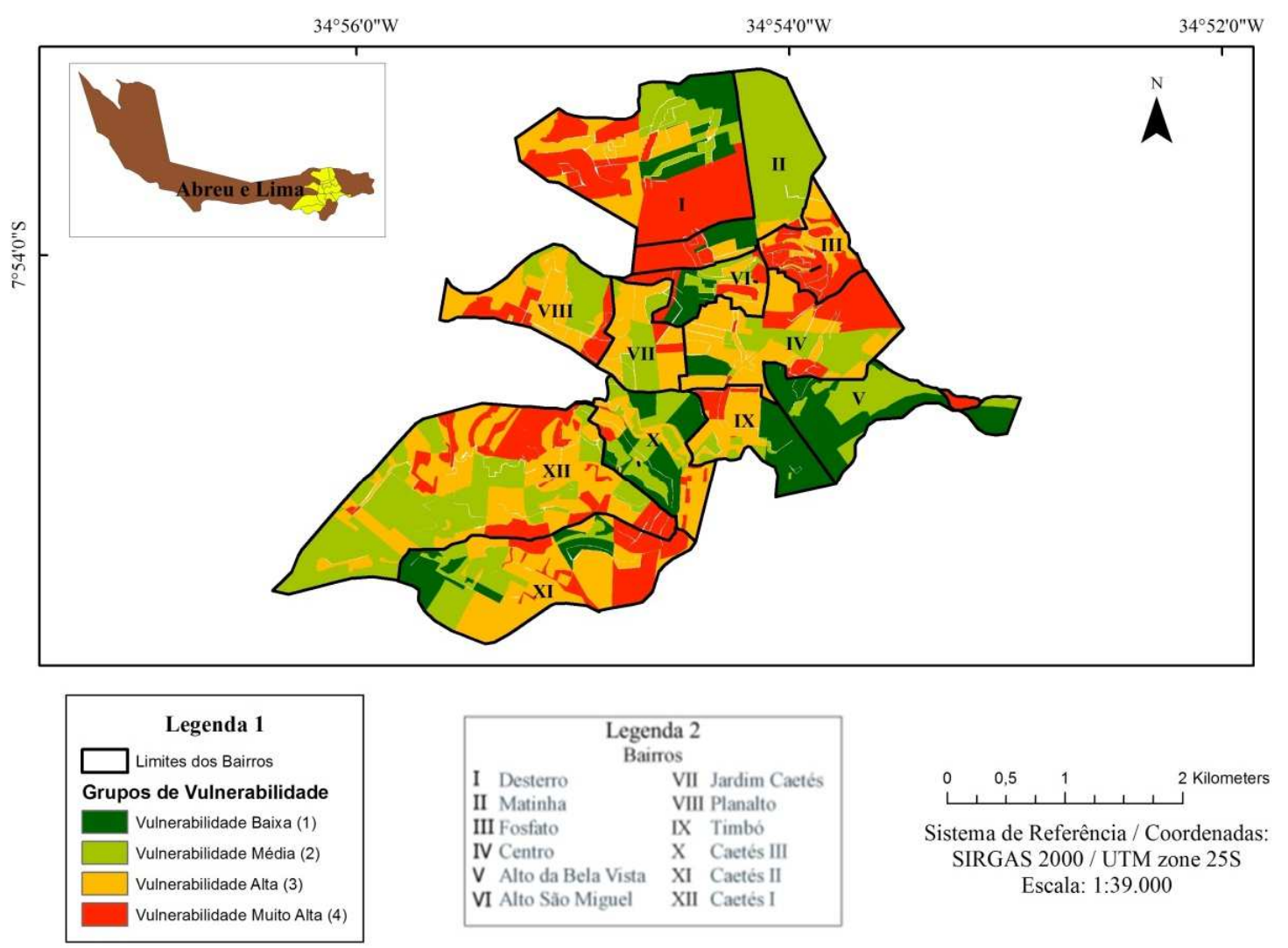


Quadro 5. Percentual de ocorrência das quatro classes de vulnerabilidade socioambiental na região urbana de

\begin{tabular}{|c|c|c|}
\hline $\begin{array}{c}\text { Grau de } \\
\text { Vulnerabilidade }\end{array}$ & $\begin{array}{c}\text { Abreu e Lima } \\
\text { Características Gerais }\end{array}$ & $\begin{array}{l}\text { Percentual de } \\
\text { ocorrência na } \\
\text { área urbana }(\%)\end{array}$ \\
\hline Baixa & $\begin{array}{l}\text { Moradias geralmente sob tabuleiros e planícies com } \\
\text { ordenamento urbano adequado e com baixa } \\
\text { vulnerabilidade dos indicadores socioambientais }\end{array}$ & 8,49 \\
\hline Média & $\begin{array}{l}\text { Moradias no geral estão localizadas em superfícies } \\
\text { estáveis: tabuleiros e planícies, por vezes em encostas com } \\
\text { ordenamento adequado. Os indicadores socioambientais } \\
\text { apresentam média vulnerabilidade }\end{array}$ & 22,84 \\
\hline Alta & $\begin{array}{l}\text { As moradias estão distribuídas em continuidades de } \\
\text { encostas e em margens de rios sem ordenamento urbano } \\
\text { adequado. Podem ser encontradas moradias em tabuleiros } \\
\text { e planícies sem ordenamento urbano. Indicadores } \\
\text { socioambientais com alta vulnerabilidade }\end{array}$ & 34,95 \\
\hline Muito Alta & $\begin{array}{c}\text { As moradias estão distribuídas principalmente em encostas } \\
\text { e em margens de rios sem ordenamento urbano e em } \\
\text { estágio incipiente de urbanização. Indicadores } \\
\text { socioambientais classificados como muito alta } \\
\text { vulnerabilidade }\end{array}$ & 33,70 \\
\hline
\end{tabular}

Já os locais que estão em vulnerabilidade muito alta seguem um padrão também encontrado no substrato real do bairro, pois são áreas que particularmente, além de grande adensamento populacional e baixa renda, são acometidos também por um considerável número de domicílios com esgoto a céu aberto. Outra característica que também gera uma alta vulnerabilidade para estes sítios no bairro de Timbó são as moradias que estão nas margens dos rios, fazendo com que estas áreas tenham uma susceptibilidade alta a inundações em épocas chuvosas. Contando ainda com a potencial transmissão de doenças de veiculação hídrica devido ao esgoto a céu aberto incorporado nestes espaços inundados (SOLA et al., 2018).

Outros bairros, como Caetés III e Centro, também possuem porções do território tanto com ocupações em áreas próximas ou em margens dos rios quanto numa grande quantidade de domicílios com esgoto a céu aberto em ambientes próximos de um rio. Estas situações, incluindo baixos indicadores socioambientais como a renda, resultam em uma alta vulnerabilidade nestes locais.

No bairro do Alto da Bela Vista, por ser um bairro que contém apenas um setor censitário, ou seja, a extensão do setor é o próprio bairro, as particularidades da vulnerabilidade socioambiental no mapa para as áreas menores não puderam ser visualizadas. Isto subestimou alguns resultados em diversos sítios heterogêneos do bairro, como é o caso das moradias em encostas e disposição de vias e casas em relevos planos sem adequação urbana no sentido norte 
do bairro. Desta forma, apenas dois grupos de vulnerabilidade foram encontrados no bairro, que foram as áreas com vulnerabilidade baixa que se localizam tanto em encostas com adequação urbana, quanto em relevos mais planos no sentido sudoeste do bairro; além de locais com vulnerabilidade média, que são justamente as habitações em encostas sem infraestrutura adequada e em vias sem pavimentação de asfalto ou granito.

Os resultados do mapa de vulnerabilidade socioambiental, em linhas gerais, refletem a realidade observável in loco, apesar de existirem alguns locais onde a vulnerabilidade foi superestimada ou subestimada, principalmente por conta das extensões dos setores censitários que muitas vezes sobrepõem áreas bastante heterogêneas. Como o exemplo de uma só média de renda associada a um mesmo setor, o qual apresenta áreas tanto com moradias sem infraestrutura adequada quanto as localizadas em tabuleiros com boa infraestrutura. Situações distintas que geralmente indicam um menor acesso de renda para as primeiras áreas.

Ainda há outra explicação para a superestimação de algumas áreas que é o uso da metodologia dos setores censitários sem extrair as áreas não construídas, como também sem aplicar pesos distintos aos indicadores socioambientais, como por exemplo: utilizar um arranjo de peso ideal entre o quantitativo populacional e a quantidade de domicílios com esgoto a céu aberto.

As supracitadas situações fazem com que alguns setores censitários que tenham proporcionalmente uma quantidade elevada de moradores sejam puxados para grupos de vulnerabilidade mais altas, o que não necessariamente pode refletir a realidade daquele sítio no resultado. Ou seja, um elevado quantitativo populacional aumenta o grau de exposição a um desastre, mas podem não estar associados aos problemas socioambientais que retroalimentam os riscos ambientais do município em análise.

Desse modo, espera-se que os resultados aqui demonstrados representem uma pequena, mas importante contribuição para a visualização e execução de planejamentos territoriais com abordagens técnico-científicas objetivando uma maior eficácia na prevenção e mitigação das vulnerabilidades dos indivíduos, consequentemente, uma redução de risco de desastres do município de Abreu e Lima. 


\section{CONCLUSÕES}

As situações de vulnerabilidade socioambiental, infelizmente, estão cada vez mais presentes nos espaços ocupados pela nossa sociedade. Advindas de aspectos e condições individuais e/ou coletivas, e tendo como consequência as causas internas e muitas vezes externas a estas pessoas e comunidades.

O presente estudo mostrou que a área urbana do município de Abreu e Lima, por estar inserido nas dinâmicas sócio territoriais do desigual Estado brasileiro, eventualmente tem marcado em seu substrato físico e no tecido social os mesmos efeitos da assimetria na distribuição de recursos essenciais para não só a sobrevivência, mas uma melhor vivência de sua população.

No mapeamento das unidades homogêneas de uso e dos padrões de ocupação, foi constatado que uma parte considerável do município está habitando locais com infraestuturas inadequadas $(25,63 \%)$. Além de cerca de $25 \%$ do território ser constituído de vegetações densas/descontínuas ou solo exposto; evidenciando assim um caráter periurbano na região urbana de Abreu e Lima. Outros cerca de 35\% estão em espaços com infraestrutura adequada. Em linhas gerais, as áreas com déficit de infraestrutura estão fixadas em sítios com alta susceptibilidade ambiental (margens de rios e encostas).

Enquanto nos mapas dos indicadores socioambientais com base nos dados do Censo do IBGE de 2010, em geral, ocorreram correlações entre os baixos valores dos indicadores socioambientais e a disposição dos setores censitários em ambientes suscetíveis à inundação e deslizamentos de terra. Ou seja, grande parte dos setores que estavam dispostos nas encostas e nas margens de rios indicavam em seus valores uma vulnerabilidade mais alta.

Face ao exposto, os resultados do mapa de vulnerabilidade socioambiental corroboram com essa relação entre os indicadores de vulnerabilidade socioambiental e a alta susceptibilidade ambiental, na medida em que há uma fixação de muitas moradias de baixo padrão de infraestrutura em áreas ambientalmente vulneráveis sem um efetivo ordenamento urbano e adequação técnica. Além de quantidades significativas de áreas com baixa vulnerabilidade ambiental, porém, com indicadores que exprimem a desigual distribuição de renda e a ineficiência da oferta dos serviços públicos básicos para a população da região urbana abreulimense. 
Neste sentido podemos afirmar que a utilização dos estudos em vulnerabilidade, conjuntamente com o emprego das técnicas em geoprocessamento são de extrema importância na integralização dos aspectos físicos e humanos do território. Pois, na análise e explicação das complexas e imbrincadas interações dos fenômenos espaciais, abordagens igualmente interligadas devem ser adotadas para efetivas resoluções dos inúmeros problemas existentes nos territórios afora.

\section{REFERÊNCIAS}

ALCÁNTARA-AYALA, I. Geomorphology, natural hazards, vulnerability and prevention of natural disasters in developing countries. Geomorphology, v. 47, n. 2-4, p. 107-124, 2002.

ALHEIROS, M. M. et al. Manual de ocupação dos morros da Região Metropolitana do Recife. Recife: Programa Viva o Morro, p. 147, 2003.

ALVES, H. P. da F. Metodologias de integração de dados sociodemográficos e ambientais para análise da vulnerabilidade socioambiental em áreas urbanas no contexto das mudanças climáticas. In: População e mudança climática: dimensões humanas das mudanças ambientais globais. Campinas: Núcleo de Estudos de População-Nepo/Unicamp, p. 75-105, 2009.

ATLAS DO DESENVOLVIMENTO HUMANO NO BRASIL., 2013. Disponível: <www.atlasbrasil.org.br/2013>. Acesso: 12 de agosto de 2020.

BRASIL. 1979. Lei n. 6.766 de 1979. Dispõe sobre o Parcelamento do Solo Urbano e dá outras Providências. Diário Oficial da República Federativa do Brasil, Poder Executivo, Brasília, DF.

BRASIL. 2012. Lei n ${ }^{\circ} 12.651$ de 2012. Dispõe sobre a proteção da vegetação nativa e dá outras providências. Diário Oficial da República Federativa do Brasil, Poder Executivo, Brasília, DF.

BUFFON, E. A. M. Vulnerabilidade socioambiental à leptospirose humana no aglomerado urbano metropolitano de Curitiba, Paraná, Brasil: proposta metodológica a partir da análise multicritério e álgebra de mapas. Saúde e Sociedade, v. 27, p. 588-604, 2018.

DESCHAMPS, M. Estudo sobre a vulnerabilidade socioambiental na Região Metropolitana de Curitiba. Cadernos Metrópole., n. 19, 2008.

FEITOSA, M. S. S. Enchentes do rio Poti e vulnerabilidades socioambientais na cidade de Teresina-PI, 2014. Disponível: https://repositorio.ufpe.br/handle/123456789/29371. Acesso: 27 dez.2019. 
FREITAS, C. M. de., et al. Vulnerabilidade socioambiental, redução de riscos de desastres e construção da resiliência: lições do terremoto no Haiti e das chuvas fortes na Região Serrana, Brasil. Ciência \& Saúde Coletiva, v. 17, p. 1577-1586, 2012.

FUNDAÇÃO SEADE. Índice paulista de vulnerabilidade social-IPVS: espaços e dimensões da pobreza nos municípios do estado de São Paulo, 2010. Disponível: http://ipvs.seade.gov.br/view/pdf/ipvs/principais_resultados.pdf. Acesso: 12 ago. 2020

G1. Moradores de Abreu e Lima denunciam interrupção da ação da Defesa Civil onde deslizamento matou cinco pessoas. https://g1.globo.com/pe/pernambuco/noticia/2019/07/25/moradores-de-abreu-e-limadenunciam-interrupcao-da-acao-da-defesa-civil-onde-deslizamento-matou-cincopessoas.ghtml> Acesso: 19 dez. 2019.

MALTA, F. S., COSTA, E. M. D., \& MAGRINI, A. Índice de vulnerabilidade socioambiental: uma proposta metodológica utilizando o caso do Rio de Janeiro, Brasil. Ciência \& Saúde Coletiva 22, 3933-3944, 2017.

MEDEIROS, M. D. de. Vulnerabilidade socioambiental no município de Natal, RN, BR. 2015. 167 f. Dissertação (Mestrado), Programa de Pós-Graduação em Geografia. Universidade Federal do Rio Grande do Norte, Natal, 2015.

MEDEIROS, F. F.; GRIGIO, A. M. Identificação das Unidades Homogêneas e Padrão da Ocupação Urbana (UHCT) como subsídio ao ordenamento territorial em Mossoró, RN—Brasil. EURE (Santiago), v. 45, n. 135, p. 245-270, 2019.

MUCCIONE, V. et al. Differentiating regions for adaptation financing: the role of global vulnerability and risk distributions. Wiley Interdisciplinary Reviews: Climate Change, v. 8, n. 2, p. e447, 2017.

OLIVEIRA, A. U. de. A lógica da especulação imobiliária. Boletim Paulista de Geografia, n. 55, p. 75-92, 2017.

OLIVEIRA, W. R. J. de; BRAGA, F. G. Estudo da vulnerabilidade socioambiental e percepção de risco dos moradores do Morro dos Piolhos-Ouro Preto-MG. Revista Espinhaço| UFVJM, p. 78-86, 2014.

OLIVER-SMITH, A. et al. A construção social do risco de desastres: em busca das causas básicas. In: MARCHEZINI, C.; WISNER, B.; LONDE, R. L.; SAITO, S.M. (Orgs). Reduction of vulnerability to disasters: from knowlwdge to action. São Carlos: RiMA Editora, 2017.

ROSSINI-PENTEADO, D. et al. Mapa de uso e ocupação do solo aplicado a prognósticos ambientais no âmbito do Projeto SIIGAL. DGUSP, AGB, UGB, ABClima, SIMPÓSIO BRASILEIRO DE GEOGRAFIA FÍSICA APLICADA, v. 11, p. 236-237, 2005.

SÃO PAULO. Estado. Sistema de classificação unidades homogêneas de cobertura da terra e uso e padrão de ocupação urbana (UHCT) e mapeamento da vulnerabilidade de áreas 
urbanas de uso residencial/comercial/serviços a eventos geodinâmicos do Estado de São Paulo. Instituto Geológico; Coordenadoria de Planejamento Ambiental/Secretaria de Meio Ambiente do Estado de São Paulo. 2016.

SILVA, D. J., COUTINHO, R. Q., SILVA, F. O. T., \& SILVA, R. R. R. Estudo GeológicoGeotécnico da Comunidade Córrego da Areia, Município de Abreu e Lima-PE, com Ênfase em Problemas de Erosão. COBRAMSEG2016, Anais, 2016. Disponível: https://plataforma.swge.com.br/PROCEEDINGS/. Acesso: 20 ago. 2020.

SOLA, F.; SABOYA, L.; COSTA, J. A. F. Vulnerabilidade socioambiental e sanitária pela contaminação dos recursos hídricos na metrópole de São Luís-Maranhão, Convención Internacional de Salud, Cuba, 2018.

TAGLIANI, C. R. A. Técnica para avaliação da vulnerabilidade ambiental de ambientes costeiros utilizando um sistema geográfico de informações. 2003. Disponível: http://repositorio.furg.br/bitstream/handle/1/3113/tecnicas.pdf?sequence=1. Acesso: 16 out.2020.

VALENTE, A. L. S. Uso de SIG na determinação de áreas com restrições à ocupação urbana na sub-bacia do Arroio Feijó, RS. In: Congresso e Feira para usuários de geoprocessamento. 1996. p. 849-856.

WISNER, B. Vulnerability as concept, model, metric, and tool. In: Oxford research encyclopedia of natural hazard science. 2016. 